\title{
Effect of increased antidepressant prescribing on suicide rate in Northern Ireland
}

\author{
Christopher B. Kelly and Thérèse Rafferty
}

\begin{abstract}
Alms and method To investigate whether changes in antidepressant prescribing have been associated with alteration in suicide rate for the period 1989-1996 in Northern Ireland. Data for antidepressant prescribing were obtained from a central unit, for Northern Ireland, using the defined daily dose system for each of the above years. The number of recorded cases of suicide and undetermined death were also obtained for this period. from Northerm Ireland coroners.

Recults There was no evidence of an association between suicide rate and antidepressant prescription $\left({ }^{2}=0.019, F\right.$ test $\left.=0.115, P=0.74\right)$, desplte antidepressant use more than tripling over the study period.

Clinical implications Even substantial increases in detection and treatment of depressive Iliness may not impinge on suicide rate. It is also possible that suicide rate may be a very poor marker of the benefits of antidepressant treatment.
\end{abstract}

Suicide has been identified as a preventable cause of death and targeted for reduction in the UK (Hawton, 1998). Several studies have suggested that a high percentage of suicides have a history of mental illness and, in particular, depressive illness (Foster et al, 1997). Notwithstanding the aetiological complexity of suicide, prevention, recognition and effective treatment of mental disorder are thought to play key roles in suicide prevention. At least one study has shown that increased detection and treatment of depressive illness have been associated with a reduced suicide rate (Rutz et al, 1989). Crosssectional analysis has suggested that the use of antidepressants reduces suicides in patients with depression (Isacsson et al, 1996). The ongoing Defeat Depression Campaign (Paykel \& Priest, 1992) aims to increase awareness of depression and methods of treatment among professionals and lay people. This has occurred at a time when there have been a variety of new and effective antidepressant treatments available. In this study it was possible to see if the changing use of antidepressants was associated with alteration of the suicide rate between 1989 and 1996 in Northern Ireland.

\section{The study}

The number of recorded cases of both suicide and undetermined deaths were obtained for Northern Ireland in each of the years 19891996 inclusive. This information was released by the General Register Office in Belfast, where it is collated from Northern Ireland coroners following inquests.

In Northern Ireland the Drug Utilisation Research Unit at The Queen's University of Belfast monitors prescribing practices throughout Northern Ireland, using data supplied from the Central Services Agency. When scripts are taken to the pharmacy, they are coded by the pharmacist and submitted monthly for payment to the Central Services Agency. The data are felt to be an accurate reflection of actual drug use (Rafferty et al, 1997). The Drug Utilisation Research Unit was able to supply details of all antidepressants prescribed yearly from 1989 to 1996 for Northern Ireland. Drugs were classified with the World Health Organization Anatomical Chemical Classification System. To monitor the utilisation of drugs, the defined daily dose (DDD) system is an internationally accepted technique (Oydvin \& Kristinnson, 1991). It is defined as the assumed average dose per day for a drug used for its main indication in adults. The DDD is a technical unit of measurement and does not reflect the prescribed (or actual) daily dose. Nevertheless, the DDD method has stood the test of time and remains the best method available for its purpose.

Simple regression was used to examine the statistical relationship between change in rate of suicide and undetermined deaths and prescription of antidepressants, for the above years in Northern Ireland.

\section{Findings}

Data on numbers of suicides, undetermined deaths and antidepressant prescription (using the DDD) for the years 1989-1996 are given in Table 1. The volume of antidepressants had more 
Table 1. Suicides, undetermined deaths and prescription of antidepressants (defined daily dose, in thousands) yearly for the period 1989-1996

\begin{tabular}{lccc}
\hline Year & Sulcides & Sulcides plus undetermined deaths & Antidepresecont prescribing \\
\hline 1989 & 116 & 134 & 4962 \\
1990 & 158 & 168 & 5678 \\
1991 & 129 & 148 & 6408 \\
1992 & 107 & 128 & 7669 \\
1993 & 129 & 151 & 9158 \\
1994 & 138 & 151 & 11214 \\
1995 & 122 & 146 & 13478 \\
1996 & 124 & 143 & 15664 \\
\hline
\end{tabular}

than tripled within the study period, the increase being predominantly related to the rise in sales of selective serotonin re-uptake inhibitors (SSRI), which, by 1996, were the most commonly prescribed group. Simple regression suggested that there was no statistically significant relationship between number of suicides and antidepressant prescription $\left(r^{2}=0.019, F\right.$ test $=0.115$, $P=0.74)$. When suicides and undetermined deaths were taken together, the relationship was essentially unchanged $\left(r^{2}=0.002, \quad F\right.$ test $=0.012, P=0.918$ ).

\section{Comment}

The above findings show that a large increase in the prescribing of antidepressants has not been associated with alteration of the suicide rate over a seven-year period in Northern Ireland. It is likely that the increased prescribing of antidepressants follows on from educational campaigns highlighting the prevalence and appropriate treatment of depressive illness. In addition, antidepressants with different sideeffect profiles and greater safety in overdose had become available during the study period.

Suicide is a complex act and, although its association with depressive illness is robust, other factors appear to influence its frequency. These factors include cultural, economic and political effects (Diekstra, 1989), which may act to obscure any effects of increased treatment for mental disorders. In addition, suicide is a rare event compared to the prevalence of depressive illness (Jenkins et al, 1998) and other mental disorders. For this reason, even greater increases in quantity of treatment (in this case, antidepressant prescribing) may be required to show an effect on suicide rate. Although the above are valid criticisms of these findings, they would also strongly question the value of suicide rate as a marker of effective mental illness management.
Indeed, the efficacy of prevention strategies targeting those at greatest risk (in this case, individuals with depressive illness at risk of suicide) has been questioned generally, because they ignore the continuum of symptomatology of those not targeted, which may also give rise to substantial morbidity (Rose. 1993).

It has been suggested that antidepressants may not be prescribed at doses that are clinically effective. This is unlikely to have affected these findings because the bulk of the increase in prescribing was for SSRIs, which do not suffer from the above handicap (Donaghue et al, 1996) probably because of the dosage regimes.

Finally, diagnosis of patients prescribed antidepressants was not available from Drug Utilisation Research Unit data. It is possible that these drugs are not being prescribed for the disorders for which they are licensed. There is evidence that this is the case from the USA (Olfson et al, 1998). Given the increased use of antidepressants for deliberate self-poisoning both in Northern Ireland (Kelly et al, 1998) and in other UK centres (Hawton et al, 1997) over the last decade, monitoring the clinical diagnoses of those prescribed antidepressant agents is important. The rise in antidepressant prescribing may not be targeted at those with depressive illness.

Despite the above limitations, it is disappointing to report that substantial increases of antidepressant treatment have not been assoclated with a decline in the suicide rate.

\section{References}

DiEkstra. R. (1989) Suicide and attempted suicide: an international perspective. Acta Psychiatrica Scandanavica, 80, 1-24.

Donaghue, J., TMuE, A. \& Wildgust, H. (1996) Crosssectional database analysis of antidepressant prescribing in general practice in the United Kingdom. British Medical Journal, 313, 860-861. 
Foster. T., Gillespie, K. \& McClelland, R. (1997) Menta disorders and suicide in Northern Ireland. British Journal of Psychiatry, 170, 447-452.

HAWTON, K. (1998) A national target for reducing suicide. British Medical Journal, 317, 156-157.

-. FAGG, J., Simkin, S., et al (1997) Trends in deliberate self-harm in Oxford. Implications for clinical services and the prevention of suicide. 1985-1995. British Journal of Psychiatry. 171. 556-560.

IsACSSON, G., BERGMAN, V. \& RICH, C. L. (1996) Epidemiological data suggest antidepressants reduce suicide risk among depressives. Joumal of Affective Disorders, 41, 1-8.

Jenkins, R., Bebbington, P., Brugha, T. S., et al (1998) British psychiatric morbidity survey. British Journal of Psychiatry, 173, 4-7.

KELLY, C., WEIR, J., RAFFERTY, T., et al (1998) Deliberate selfpoisoning presenting at Craigavon Area Hospital 19761996: relationship to drug prescribing. Proceedings of the Annual Meeting of the Royal College of Psychiatrists, pp. 45-46. London: Royal College of Psychiatrists.

Olrson, M., Marcus, S., Pincus, H., et al (1998) Antidepressant prescribing practices of outpatient psychiatrists. Archives of General Psychiatry. 63. 310-316.

OYDVIN, K. \& Kristinnson, A. (1991) Guidelines for DDD. Oslo: World Health Organization Collaborating Centre for Drug Statistics Methodology.
PAYKel, E. \& PRIEST, R. (1992) Recognition and management of depression in general practice: consensus statement. Brttish Medical Journal, S06. 1198-1202.

RAFFERTY, T., MCGAVOCK, H. \& WILSON-DAVIS, K. (1997) Temporal trends in drug use in one UK region, revealed by chemical group matching. Pharmacoepidemiology and Drug Safety, 6, 93-100.

Rose, G. (1993) Mental disorder and the strategles of prevention. Psychological Medicine, 23, 553-555.

RUTZ, W., VAN KNORRING, L. \& WALINDER, J. (1989) Frequency of suicide on Gotland after systematic postgraduate education of general practitioners. Acta Psychiatrica Scandinavica, 80, 151-154.

*Christopher B. Kelly, Consultant Psychiatrist, and Thèrèse Rafferty, Reserach Associate, Drug Utilisation Research Unit, The Queen's University of Belfast, Whitla Medical Building, 97 Lisburn Road, Belfast BT9 7BL

*Correspondence

\title{
Management of psychiatric in-patient violence in the Anglia region
}

\author{
Implications for record-keөping, staff training and victim \\ support
}

\author{
J. H. Dowson, J. Butler and O. Williams
}

\begin{abstract}
Aims and method A total of 384 incidents of violence against the person (six 'serious' and 378 'mild'), by adult in-patients in general psychiatric units (GPUs) and learning disability units (LDUs) in 10 National Health Senvice trusts in the Anglia region, were evaluated by intenviews with staff and examination of records. Results The findings, when compared with standards derived from previous recommendations, showed deficiencles in the documentation of incidents (there was no satisfactory written record of physical restraint for $97 \%$ of incidents in GPUs and $85 \%$ in LDUs).
\end{abstract}

in the training of staff in 'control and restraint' procedures if two or more staff were involved in physical restraint, for $3 \%$ of incidents in GPUs and $100 \%$ in LDUs, the staff had recelved no training within the previous 12 months) and in policies for victim support (there was no written pollcy that included procedures for victim support in relation to $84 \%$ of incidents in GPUs and $\mathbf{4 4 \%}$ in LDUs).

Clinical implications Trusts should consider reviewing their policies on the prevention and management of violence, particularty in relation to staff training. 